\title{
Steroids and COVID-19: We Need a Precision Approach, Not One Size Fits All
}

Grant W. Waterer · Jordi Rello

Received: August 12, 2020 / Published online: September 16, 2020

(C) The Author(s) 2020

\section{ABSTRACT}

COVID-19 is a new infectious disease causing severe respiratory failure and death for which optimal treatment is currently unclear. Many therapies have been proven to be ineffective; however, promising findings related to corticosteroid therapy have been published. Analysis of published data including in this issue suggests that therapy with corticosteroids in the range of $6 \mathrm{mg}$ of dexamethasone (or equivalent) per day likely has a positive effect in patients requiring mechanical ventilation but there remains considerable doubt in patients over the

Digital Features To view digital features for this article go to https://doi.org/10.6084/m9.figshare.12867233.

G. W. Waterer $(\bowtie)$

University of Western Australia, Perth, Australia

e-mail: grant.waterer@uwa.edu.au

G. W. Waterer

Northwestern University, Chicago, IL, USA

J. Rello

Centro de Investigación Biomedica en Red

(CIBERES), Instituto de Salud Carlos III, Madrid, Spain

J. Rello

Vall d'Hebron Institute of Research (VHIR),

Barcelona, Spain

J. Rello

Clinical Research, CHU Nîmes, Université

Montpellier-Nîmes, Nîmes, France age of 70, in patients with diabetes and patients with milder disease. Clinicians must consider the individual potential risks and benefits of corticosteroid in patients with COVID-19 rather than routinely using them until more data is available.

Keywords: ARDS; Coronavirus; Covid-19; Pneumonia; Precision medicine; RCT; SARS; Therapy

\section{Key Summary Points}

Steroids should not be given to every patient with COVID-19.

More data is needed in specific patient cohorts.

A benefit of corticosteroids has not been established in those over 70 years of age.

Hyperglycemia is a significant risk in individuals with diabetes and this subgroup of patients has not been well studied for a risk-benefit analysis of steroids.

Longer outcomes than 28 days are required to properly assess whether corticosteroid therapy truly improves patient outcomes. 


\section{DIGITAL FEATURES}

This article is published with digital features to facilitate understanding of the article. To view digital features for this article go to https://doi. org/10.6084/m9.figshare.12867233.

COVID-19 has posed a challenge not seen in the western world from an infectious disease since at least the polio epidemics of the 1940s and 1950s and in scale of mortality and morbidity not since the 1918 influenza pandemic. The initial response by the medical and scientific community was far less than exemplary. Tens if not hundreds of thousands of patients have been given a huge array of experimental therapies in all kinds of combinations, often with minimal scientific support of efficacy, in a completely haphazard manner that prohibits any assessment of their effect on outcomes [1]. Across multiple countries physicians unlearnt decades of progress in evidence-based medicine in the face of a new challenge and a desperate desire to "do something".

Now, more than 6 months into the COVID19 pandemic, we are finally seeing research data that is robust enough to guide therapeutic decisions. Early leading candidates lopinavir and ritonavir appear to be ineffective [2], as is hydroxychloroquine [3, 4]. Remdesivir may have some benefit in reducing the duration of symptoms in milder disease but does not appear to significantly alter the course of severe disease or reduce mortality [5-8], although further studies are awaited. Tocilizumab has also apparently failed to reduce mortality or severity of disease in COVID-19 in the pivotal phase III trial but full results are yet to be published [9].

The randomised evaluation of COVID-19 therapy (RECOVERY) collaborative recently published their analysis of dexamethasone as one arm of an open-label, platform trial in COVID-19 [10]. The dose of steroid used, $6 \mathrm{mg}$ of dexamethasone or approximately $32 \mathrm{mg}$ of methylprednisolone, for up to 10 days is important as significantly higher doses were used in China [11] earlier in the epidemic and daily doses of $60 \mathrm{mg}$ of methylprednisolone have been consistently associated with higher mortality and superinfections (such as invasive aspergillosis) in primary influenza pneumonia due to seasonal [12] and pandemic influenza A H1N1pdm infection [13]. While the RECOVERY study showed a small mortality benefit to dexamethasone therapy $(2.8 \%$ absolute difference overall), there are a number of concerns regarding the data and its interpretation. The overall mortality in RECOVERY appears to be quite high, especially in the milder $(17.8 \%)$ and intubated (40.7\%) cohort placebo groups, compared to some centres $[14,15]$, questioning the likely benefit of steroids in optimal conditions of care. Mortality was also measured at 28 days, despite evidence that adverse impacts of steroid administration in other acute conditions may be seen up to 90 days [16]. Perhaps not surprisingly, no benefit was observed in patients who were started on therapy prior to requiring oxygen. Equally, the RECOVERY cohort was quite young (mean age 59 years) and it should be noted that stratified analysis of older age groups showed no benefit of steroid therapy in patients aged over 70 years. Hyperglycaemia, a common side effect of corticosteroids, is associated with worse outcomes in COVID-19 [17]; however, despite 25\% of subjects in the RECOVERY trial having diabetes, this subset of patients was not analysed separately.

Adding further caution to the use of steroids in COVID-19, an even more recent randomised, placebo-controlled, double-blind study of $0.5 \mathrm{mg} / \mathrm{kg}$ of methylprednisolone conducted in Brazil in 393 patients found no difference in 28-day mortality and patients on steroids required more insulin therapy [18]. In a modified intention to treat analysis (excluding patients randomised but who never received a first dose of steroids or placebo), Jeronimo et al. [18] observed that 28-day mortality was $38.2 \%$ in the placebo group and $37.1 \%$ in the methylprednisolone group $(p=0.629)$. Mortality at day 7 showed a trend to better outcomes with steroids $(16.5 \%$ vs $23.6 \%, p=0.089)$ but this had largely reversed by day $14(27.3 \%$ vs $31.7 \%, p=0.29$ ). The RECOVERY study cohort and the Brazil study cohort were, however, significantly different. The Brazil cohort were on average about 10 years younger than in 
RECOVERY, were significantly less likely to have heart disease (7\% vs $28 \%$ ), and appear to have significantly more severe disease at enrolment $(33.8 \%$ on mechanical ventilation vs $15.5 \%)$. Clearly more data is required to determine the subsets of patients with COVID-19 who benefit from steroid therapy.

In this edition, $\mathrm{Li}$ et al. provide further data on the role of corticosteroid pulse therapy in COVID-19 [19]. In a retrospective study of 475 patients with non-severe COVID, essentially those without significant respiratory failure or respiratory distress, they confirm that there was no improvement in outcomes. Concerningly virus clearance time and length of hospital stay were significantly prolonged in those receiving corticosteroids, with significant implications for nosocomial spread and hospital resource utilisation. As expected with a retrospective study, the steroid and non-steroid groups were not well matched, suggesting a potential selection bias, with the steroid cohort being older and having more derangement of key blood markers of infection severity, like lymphocyte count, lactate dehydrogenase and C-reactive protein. Significant differences also existed in the number and type of other experimental therapies used in each group. While a propensity analysis was used to try and correct for these key confounders, care must be taken to not overextrapolate the findings of Li et al., in absence of a randomized clinical trial of steroid pulses. Comparing the results of the RECOVERY collaborative [10] and those of $\mathrm{Li}$ et al. [19] is problematic in that the dose of corticosteroid used in the latter was variable, and $0.5-1 \mathrm{mg} /$ $\mathrm{kg}$ /day of methylprednisolone would have been substantially higher than that in the RECOVERY trial. Long follow-up is also lacking, suggesting underdetection of potential adverse events. The interaction with coagulation alterations and the concomitant use of anticoagulant therapy, remdesivir use, or the different oxygenation strategies, also all require further clarification.

How should clinicians interpret the data published so far? Despite reservations about the data as described above, based on the RECOVERY trial [10] because of its large numbers, and because of other supportive retrospective data
[20], it seems reasonable to use corticosteroids at a dose not exceeding $6 \mathrm{mg}$ of dexamethasone (or equivalent) for up to 10 days in patient requiring mechanical ventilation or with rapidly progressive respiratory failure. If further studies support the data from Jeronimo et al. [18] then this approach will need to be reconsidered. However, in patients with milder disease, and possibly the more elderly and individuals with diabetes, the absence of longerterm follow-up and the data presented by $\mathrm{Li}$ et al. [19] make the routine use of corticosteroids still questionable and with an urgent need for randomized clinical trials comparing different dosage strategies in different patient subsets. All three studies represent a meaningful contribution to the advance of therapy because they identify different outcomes in different subpopulations, emphasizing the need to deploy efforts to identify different phenotypes and biomarker thresholds, such as C-reactive protein or interleukin-6 [21].

Death in SARS-CoV-2 infection is more often a fatal complication of a dysregulated immune response with the role of pathogen virulence still to be determined. Regardless mortality remains high despite remdesivir use and invasive mechanical ventilation. Thus, usefulness of potential adjunctive therapy in specific subset of patients, either to prevent disease progression or rescue of severe cases, is an unmet clinical need. The available data reported by $\mathrm{Li}$ et al. [13] and the RECOVERY trial [10] are a clear call to individualize different steroid approaches depending of the host. Thus, a theranostic approach covering both diagnostic and therapy is strongly recommended.

\section{ACKNOWLEDGMENTS}

Funding. No funding or sponsorship was received for this study or publication of this article.

Authorship. All named authors meet the International Committee of Medical Journal Editors (ICMJE) criteria for authorship for this article, take responsibility for the integrity of 
the work as a whole, and have given their approval for this version to be published.

Disclosures. Grant Waterer and Jordi Rello declare no personal, financial, commercial, or academic conflicts of interest.

Compliance with Ethics Guidelines. This article is based on previously conducted studies and does not contain any studies with human participants or animals performed by any of the authors.

Open Access. This article is licensed under a Creative Commons Attribution-NonCommercial 4.0 International License, which permits any non-commercial use, sharing, adaptation, distribution and reproduction in any medium or format, as long as you give appropriate credit to the original author(s) and the source, provide a link to the Creative Commons licence, and indicate if changes were made. The images or other third party material in this article are included in the article's Creative Commons licence, unless indicated otherwise in a credit line to the material. If material is not included in the article's Creative Commons licence and your intended use is not permitted by statutory regulation or exceeds the permitted use, you will need to obtain permission directly from the copyright holder. To view a copy of this licence, visit http://creativecommons.org/licenses/bync/4.0/.

\section{REFERENCES}

1. Waterer GW, Rello J, Wunderink RG. COVID-19: first do no harm. Am J Respir Crit Care Med. 2020;201(11):1324-5.

2. Cao B, Wang Y, Wen D, et al. A trial of lopinavirritonavir in adults hospitalized with severe Covid19. N Engl J Med. 2020;382(19):1787-99.

3. Boulware DR, Pullen MF, Bangdiwala AS, et al. A randomized trial of hydroxychloroquine as postexposure prophylaxis for Covid-19. N Engl J Med. 2020;383:517-25.

4. Cavalcanti AB, Zampieri FG, Rosa RG, et al. Hydroxychloroquine with or without azithromycin in mild-to-moderate Covid-19. N Engl J Med. 2020. https://doi.org/10.1056/NEJMoa2019014.

5. Grein J, Ohmagari N, Shin D, et al. Compassionate use of remdesivir for patients with severe Covid-19. N Engl J Med. 2020;382:2327-36.

6. Wang Y, Zhang D, Du G, et al. Remdesivir in adults with severe COVID-19: a randomised, double-blind, placebo-controlled, multicentre trial. Lancet. 2020;395(10236):1569-78.

7. Beigel JH, Tomashek KM, Dodd LE, et al. Remdesivir for the treatment of Covid-19-preliminary report. N Engl J Med. 2020. https://doi.org/10.1056/ NEJMoa2007764.

8. Spinner CD, Gottlieb RL, Criner GJ, et al. Effect of remdesivir vs standard care on clinical status at 11 days in patients with moderate COVID-19: a randomized clinical trial. JAMA. 2020. https://doi.org/ 10.1001/jama.2020.16349.

9. Roche. Roche Provides an update on the phase III Covacta trial. https://www.roche.com/media/ releases/med-cor-2020-07-29.htm. Accessed 8 Aug 2020.

10. Recovery Collaborative Group, Horby P, Lim WS, et al. Dexamethasone in hospitalized patients with Covid-19-preliminary report. N Engl J Med 2020. https://doi.org/10.1056/NEJMoa2021436.

11. Liu J, Zheng X, Huang Y, Shan H, Huang J. Successful use of methylprednisolone for treating severe COVID-19. J Allergy Clin Immunol. 2020;146: $325-7$.

12. Moreno G, Rodriguez A, Reyes LF, et al. Corticosteroid treatment in critically ill patients with severe influenza pneumonia: a propensity score matching study. Intensive Care Med. 2018;44(9):1470-82.

13. Martin-Loeches I, Lisboa T, Rhodes A, et al. Use of early corticosteroid therapy on ICU admission in patients affected by severe pandemic (H1N1)v influenza A infection. Intensive Care Med. 2011;37(2):272-83.

14. COVID-19 National Incident Room Surveillance Team. COVID-19, Australia: epidemiology report 20 (fortnightly reporting period ending 5 July 2020). Commun Dis Intell. 2018;2020:44.

15. Barrasa H, Rello J, Tejada S, et al. SARS-CoV-2 in Spanish intensive care units: early experience with 15-day survival in Vitoria. Anaesth Crit Care Pain Med. 2020. https://doi.org/10.1016/j.accpm.2020. 04.001 .

16. Waljee AK, Rogers MA, Lin P, et al. Short term use of oral corticosteroids and related harms among adults 
in the United States: population based cohort study. BMJ. 2017;357:j1415.

17. Zhu L, She ZG, Cheng X, et al. Association of blood glucose control and outcomes in patients with COVID-19 and pre-existing type 2 diabetes. Cell Metab. 2020;31(6):1068-77.

18. Jeronimo CMP, Farias MEL, Val FFA, et al. Methylprednisolone as adjunctive therapy for patients hospitalized with COVID-19 (Metcovid): a randomised, double-blind, phase IIb, placebo-controlled trial. Clin Infect Dis. 2020. https://doi.org/ 10.1093/cid/ciaa1177.
19. Li Q, Li W, Jin Y, et al. Efficacy evaluation of early, low-dose, short-term corticosteroid in adults hospitalized with non-severe COVID-19 pneumonia. Infect Dis Therapy. 2020.

20. Fadel R, Morrison AR, Vahia A, et al. Early short course corticosteroids in hospitalized patients with COVID-19. Clin Infect Dis. 2020. https://doi.org/ 10.1093/cid/ciaa601.

21. Rello J, Beliato M, Storti E, Serrano R. Clincial phenotypes of SARS-CoV-2: implications for clinicians and researchers. Eur Respir J. 2020;55: 2001028. 